\title{
O CONCEITO DE POLIFONIA EM BAKHTIN - O TRAJETO POLIFÔNICO DE UMA METÁFORA
}

\begin{abstract}
Artur Roberto Roman *
Queiramos ou não, as metáforas seduzem a razāo. São imagens particulares e remotas que insensivelmente se convertem em esquemas gerais.
\end{abstract}

(Bachelard-1948:93)

\section{INTRODUÇÃO}

1

polifonia é um conceito muito caro à lingüística contemporânea. Utilizada metaforicamente por Bakhtin, na análise da obra de participa hoje do acervo conceptul de diversos ramas da ciencia da lie guagem.

A leitura de variados trabalhos que abordam a questão da polifonia em lingüística mostra que não há, no entanto, homogeneidade em sua aplicação. Juntamente com a tendência redutora, há aqueles que ampliam o conceito, chegando a adulterá-lo.

O objetivo deste trabalho é recuperar o sentido da polifonia trazido da música medieval e mostrar a sua aplicação dentro do corpo teórico desenvolvido por Bakhtin, bem como apontar improcedências na tentativa de aproximação de linhas teóricas, através da articulação dessa metáfora.

* Aluno de Pós-Graduação, Mestrado em Lingüistica de Língua Portuguesa - UFPR. 


\section{POLIFONIA NA MÚSICA}

Polifonia é o nome dado a um estilo de música que se desenvolveu na Idade Média. Embora não haja unanimidade entre os estudiosos com respeito à origem da polifonia, não parece haver dúvidas quanto às suas raizes populares e também quanto à sua oposição ao canto monódico da Igreja, o canto gregoriano. ${ }^{1}$

Os primeiros documentos descrevendo rudimentos de polifonia datam do século IX. No organum, canto popular que começa a aparecer a partir desse periodo, acrescenta-se ao canto monódico, unissono, uma segunda voz. Cantado, portanto, pelo menos por dois cantores, cada nota da melodia principal é contracantada por uma única nota da voz superior. Essas melodias eram escritas na época sob a forma de pontos, dai o sentido original da palavra contraponto: ponto contra ponto.

Datam do início do século XII os primeiros documentos de uma polifonia de duas vozes em que a independência ritmica (duração das notas e acento das palavras) vai aparecer. A segunda voz passa a rebater nota por nota a melodia do cantochāo em movimentos não apenas paralelos, mas variados, contrários, obliquos.

A partir da chamada Escola de Notre-Dame de Paris, no periodo gótico, passaram a desenvolver-se várias outras formas musicais polifonnicas, com estruturas em que a contestaçāo ao canto gregoriano $\mathfrak{e}$ levada a um grau ainda muito mais radical. A grande forma polifónica desse periodo é um gênero de composição em que as palavras determinam as linhas melódicas; logo se chamou a este gênero de composição moteto (de mot - palavra).

Pelos meados do século XIII, as vozes dos motetos passam a se diferenciar, tanto ritmica como melodicamente. Essa independencia das vozes vai permitir que nāo só uma melodia trovadoresca e um canto gregoriano apareçam simultaneamente numa mesma peça, mas também que uma das vozes cante um hino em latim, enquanto outra canta uma canção em francès. Essa ausência de identidade entre as linhas melódicas, que se cruzam constantemente, permite formar um verdadeiro trançado de linhas

1 Tanto o canto gregoriano, quanto a polifonia săo cantos modais. As músicas modais são reiterativas, repetitivas e monótonas. Seu desenvolvimento é circular em tomo de uma tônica fixa. Nessa circularidade estática, em tomo de um eixo harmónico fixo, a melodia modal caminha para o que Wisnik chama de um "nāo-tempo", ou seja, "um tempo circular do qual é dificil sair, depois que se entra nele, por que è sem fim." (Wisnik-1989, p.36) 
independentes, num claro contraste com a uniformidade e a planura do cantochão, o canto gregoriano. A individualização das partes, no que se refere ao texto, também vai se tornando mais acentuada. Há motetos em que uma voz canta um louvor a Virgem Maria, enquanto outra propaga as belezas de uma prostituta. Nessa politextualidade, linguagens diferentes se interpenetram, confrontando-se o erudito e o popular, o sacro e o profano.

A politextualidade, que é um aspecto essencial do moteto, bem como a independência total, tanto melódica como rítmica, entre as vozes, será uma constante através dos séculos da era gótica e uma caracteristica definidora dessa modalidade de polifonia.

A polifonia era uma linguagem dinâmica e mutável, flutuante e ativa, apropriada, portanto, para expressar a percepção carnavalesca do mundo, que possuía o homem medieval, ${ }^{2}$ oposta a qualquer idéia de acabamento e perfeição, que caracterizava o canto gregoriano.

\section{HOMOFONIA NA MÚSICA}

A partir do século XIV (Ars Nova), a evolução do sistema de notação musical vai permitir uma maior complexidade nas composições polifônicas, levando a um gradual afastamento de suas raízes populares. O cada vez mais intrincado entrelaçamento das vozes vai tomar impossível o entendimento das palavras, o que acaba por preocupar não só o Clero, (que, incapaz de combatê-la, já havia incorporado a polifonia), como também os compositores não ligados à Igreja, desejosos de exprimir através de palavras inteligiveis, o sentido emocional dos textos musicados. O Concilio de Trento (1583), no bojo da Contra-Reforma, dá as bases para que a Igreja passe a privilegiar na música o estilo homofônico, ao invés da polifonia. Isto porque na homofonia um mesmo texto é cantado simultaneamente por todas as vozes, o que possibilita uma apresentação mais clara das palavras, tocando mais os fiéis. (Wisnik, 1989, p.117/19).

A preocupação com a inteligibilidade do texto vai permitir a observação da relação vertical entre as vozes, e essa percepção da combinação de sons simultâneos desenvolveria o sentimento de harmonia.

2 Para uma melhor compreensão do pensamento do homem medieval e da cultura popular da Idade Média, ver Bakhtin-1987. 
Enquanto polifonia é uma multiplicidade de vozes independentes, imiscíveis e superpostas cantando textos variados, homofonia são várias vozes cantando simultaneamente o mesmo texto, subordinadas à harmonia que garante a unidade musical através dos acordes. Incorporando paulatinamente a homofonia, o sistema tonal vai se consolidar ao longo dos séculos XVI, XVII estabelecendo-se definitivamente por volta de $170 .^{3}$

\section{POLIFONIA NA LITERATURA}

Bakhtin desenvolve o conceito de polifonia em Problemas da Poética de Dostoiéviski (PPD). Segundo Bakhtin, é característica do romance ser plurivocal. Estudando Dostoiévski, Bakhtin observou que o seu discurso romanesco não é apenas plurivocal - há algo mais além dessa plurivocidade: as vozes dos personagens apresentam uma independência excepcional na estrutura da obra. Como diz Bakhtin, "é como se soassem ao lado da palavra do autor". Observou mais que as múltiplas consciências que aparecem no romance mantêm-se eqüipolentes, ou seja, em pé de absoluta igualdade, sem se subordinarem à consciēncia do autor. Também os mundos que povoam os seus romances se combinam numa unidade de acontecimento, porém mantendo a sua imiscibilidade.

Ao enfatizar o caráter dialógico aberto do universo artístico de Dostoiévski, Bakhtin destaca outra característica de seu estilo: a inconclusibilidade. Na trama construida por Dostoiévski, não há uma superação dialética entre a multiplicidade de consciência que povoa os seus romances; os problemas e as contradições nāo se resolvem, continuam "irremediavelmente contraditórios"(Bakhtin-1981, p.24). O romance polifónico de Dostoićvski não tem uma apoteose.

Esses procedimentos artísticos especiais de construção do romance de Dostoiévski - a inconclusibilidade temática, a independéncia, imiscibilidade e eqüipoléncia das vozes - vão mostrar uma estreita similitude com as características da polifonia medieval, daí a utilização da metáfora.

3 A melodia tonal é elaborada em tomo de acordes, nảo se fixa em uma tônica. Contrapõe à tónica outras notas, a dominante a subdominante, (existe uma hierarquia entre as notas!) que ensejam novos acordes com novas possibilidades melódicas. Na música tonal há um movimento progressivo, que vai evoluindo buscando uma resoluçāo. Ao contrário da música modal, cla apresenta um "fundamento dinàmico, progressivo, telcológico, perspectivistico." (Wisnik-1989, p. 106) 
Nessa obra, Bakhtin discorda da comparação que Komaróvitch faz entre a polifonia de Dostoiévski e a combinação contrapontística de vozes da fuga. ${ }^{4}$ Diz Komaróvitch, citado por Bakhtin, que a unidade artística do romance dostoievskiano se faz, assim como as vozes da fuga, mediante a subordinação teleológica dos elementos constitutivos da obra (romance ou música). Bakhtin diz ser incorreta essa interpretação. Explica que a essência da polifonia consiste justamente no fato de que as vozes permanecem independentes e, como tais, combinam-se numa unidade de ordem superior à da homofonia, sem a "subordinação teleológica".

Leonid Grossman, a quem Bakhtin faz referência em PPD, crítico literário russo dedicado ao estudo de Dostoiévski, no ensaio Dostoiévski Artista também ressaltava o caráter musical da composição de Dostoiévski:

A lei de composição da obra de Dostoiévski poderia ser representada graficamente, como uma horizontal do entrecho em desenvolvimento, interceptada pelas verticais dos episódios tumultuosos, que erguem a ação para a altura, e que parecem transportá-la para um novo plano, onde a linha do argumento, paralela à primeira, em breve também se precipitará para o alto, em virtude da explosão de uma nova ocorrència incomum. Obtém-se uma linha de composição em degraus, que não cessa de elevar o entrecho até a sua conclusāo definitiva, na catástrofe final c na catarse concludente. (Grossman-1967, p. 36)

Essa resolução catártica, além da dinâmica progressiva, são características do tonalismo, o que afasta a comparação da polifonia gótica. Grossman, quando destaca a "estrutura polifônica" da obra de Dostoiévski, com certeza, não se refere à polifonia modal. Tanto que sua análise do método composicional de Dostoiévski se fixa especialmente nos elementos constitutivos de sua obra, sem enfatizar a relação entre as vozes no romance.

Komaróvitch, Grossman e Bakhtin falam de polifonias diferentes. A dos primeiros é a polifonia tonal que busca uma resolução final; a de Bakhtin é a polifonia medieval gótica, modal, inconclusa.

4 A fuga é polifônica também, mas diferente do moteto. Sua expressão maior foi Bach. A polifonia de Bach é construída dentro do espaço tonal(Kiefer-1976). Talvez Komaróvitch preferisse colocar ao lado de Dostoiévski um grande nome como Bach, do que comparara sua composiçào com os motetos populares da Idade Média! 


\section{POLIFONIA E CARNAVALIZAÇÃO}

A polifonia de Dostoiévski vincula-se mais fortemente à polifonia gótica, quando analisados $\propto s$ aspectos de camavalização de seu romance. ${ }^{5}$ A imagem carnavalesca tende a abranger os dois membros da antitese: nascimento-morte, mocidade-velhice, alto-baixo, face-traseira, elogioimpropério, afirmaçāo-negação, trágico-cōmico, etc. Segundo Bakhtin, é assim que se pode definir o próprio princípio da obra de Dostoiévski: "Tudo em seu mundo vive em plena fronteira com o seu contrário."(Bakhtin-1981, p.153)

Vê-se que é a polifonia gótica do moteto e não outra, o estilo adequado para expressar esse princípio carnavalesco da obra de Dostoiévski, ou seja, essa multiplicidade de vozes, essas diferenças, ambigüidades, "num franco processo de mixagem de vozes, textos, línguas, ritmos e índices sociais..."(Wisnik-1989.p. 112)

\section{HOMOFONIA NA LITERATURA}

Bakhtin coloca o gênero essencialmente novo do romance polifónico criado por Dostoiévski em oposiçāo às formas jả constituídas do romance europeu, principalmente do romance monológico (homofônico). O exemplo que cita de romance homofônico é Tolstói. ${ }^{6}$ Aqui a metáfora musical utilizada por Bakhtin é bem ilustrativa: no romance homofönico ou monológico, as vozes perdem a sua imiscibilidade e as consciências se tornam dependentes da consciència una do autor.

5 Bakhtin denomina de carnavalizaçāo da liseratura a transposiçāo para a literatura da linguagem simbólica (concreto-sensorial) das festas populares ritualisticas, de base camavalesca. Estes festejos, embora apresentem variaçöes de natureza cultural e histórica, caracterizam-se fundamentalmente pela inversāo da ordem habirual da vida, quando as regras sociais $\mathrm{e}$ as proibiçōes sio suspensas e o mundo "é virado às avessas". Ver PPD, p. 105 a $155 \mathrm{e}$ Bakhtin- 1987.

6 Kothe (1981) afirma, em sala critica a Bakhtin, que o romance de Tolstớ é tảo polifónico quanto o de Dostoiévski. Neste nosso trabalho não estả em questão a análise literária feita por Bakhtin. mas somente a aplicaçào que faz da metafora musical. 


\title{
POLIFONIA NA PSICANÁLISE
}

\author{
A psicanálise vai buscar também na música o modelo para explicar \\ a manifestação do inconsciente:
}

Se nós utilizarmos uma comparação de ordem musical, o canto do inconscicnte não é o contracanto de uma fuga ou os harmônicos de uma linha melódica: o canto do inconsciente é a música de jazz ouvida, tendo por detrás um quarteto de Haiden, vindo de um rádio mal sintonizado. (S.Leclaire.La réalité du désir. Apud Authier-Revuz-1987, p. 135)

E conclui Leclaire:

dentro do desenvolvimento de uma só cadeia material, se escuta ao mesmo tempo diversos discursos sem que exista qualquer terreno de interpretação entre eles. (S.Leclaire et D.Lévy. Le port de Djakarta.Apud Authier-Revuz-1987, p. 135)

Embora a tenha tão bem caracterizado, Leclaire não utiliza o termo polifonia. É Lacan, apoiado nos estudos de Saussure sobre os anagramas, que vai explicitamente utilizar a metáfora:

a linearidade que F. de Saussure considera como constituinte da cadeia do discurso, conforme a sua emissão por uma única voz. e na horizontal, onde se inscreve em nossa escrita, se ela $\dot{c}$ necessária de fato, não é suficiente (...) basta escutar a poesia, o que era sem dúvida o caso de Saussure para que ai se faça ouvir uma polifonia, e ver que todo discurso alinha-se sobre as várias pautas de uma partitura (1978, p. 233-4).

Lacan reforça a analogia com a noção do contraponto musical:

Não há, com efeito, nenhuma cadeia significante que nảo sustente como pendendo na pontuação de cada uma de suas unidades tudo o que se articule de contextos atestados, na vertical, por assim dizer, desse ponto (p. 234).

7 Ver Starobinski(1974). 
É possivel, portanto, falar-se em um uso metafórico da polifonia, tanto por Bakhtin quanto por Lacan.

\section{POLIFONIA NA LINGÜÍSTICA}

Quem tem o mérito de especificar o uso dessa polifonia lacaniana, explorando-a, com produtividade, na lingüística, é Jacqueline AuthicrRevuz, quando busca a aproximação do dialogismo de Bakhtin com a abordagem psicanalitica do sujeito de Lacan (Authier-Revuz-1982).

Se a construção dessa identidade está sujeita, como ela própria reconhece, a contradiçōes, não será devido ao uso indevido da metáfora. Authier procura sustentar essa conexão no reconhecimento de ambos da heterogeneidade estrutural de toda formação discursiva, consubstanciada na presença do outro na linguagem do sujeito. Se pode ser questionado o seu esforço teórico, deve-se reconhecer que tomou operativo o uso do conceito. ${ }^{8}$

$O$ trabalho de Authier-Revuz parece animar a argumentação teórica de Osvald Ducrot, que lhe faz créditos na apresentaçāo de sua própria tcoria da polifonia.

\section{A POLIFONIA EM DUCROT}

Ducrot, no Esboço de uma Teoria Polifônica da Enunciaçāo (1987), se propõe a questionar um pressuposto que, segundo ele, subjaz à chamada "lingüística moderna", qual seja, a tese da "unicidade do sujeito falante" (p. 161).

Ducrot vai distinguir num enunciado, além do sujeito falante, autor efetivo do enunciado (ser empirico), o locutor (ser do discurso) e o enumciador, o sujeito dos atos ilocutórios. ${ }^{9}$ Para Ducrot, o sentido do enunciado

8 Authier distingue a heterogeneidade constitutiva da heterogeneidade mostrada no discurso, discriminando "a polifonia de todo discurso que necessariamente se alinha sobre os muitos planos de uma partitura" dos "efeitos" de polifonia que permitem certas formas de hetcrogencidade mostrada." (1990, p. 32).

9 Maingueneau(1990) no artigo Polyphonie discute didaticamente esses "trois status" do sujeito falante em Ducrot. A única referencia feita a Bakhtin está na introdução do trabalho. quando o autor lembra que a noçào de polifonia desenvolvida por Ducrot é emprestada do tratzalho de Bakhtin. 
é um conjunto de indicações sobre a enunciação, e nessa descrição da enunciação, o enunciado assinala, além do locutor, os enunciadores que, ao ocupar papéis ilocucionais, se expressam numa pluralidade de vozes ( $p$. 172). Essa manifestação de diversas vozes presentes na enunciação está prevista no sistema da língua e se dá através de marcas lingüísticas.

Para os objetivos deste nosso artigo, deve-se destacar que a caracterização dessa superposição de vozes que se manifesta na enunciação, como polifonia, não guarda correspondência adequada com a polifonia musical. ${ }^{10} \mathrm{O}$ atributo polifônico implicaria, manifestada na enunciação, uma multiplicidade de vozes que, além de imisciveis, explicitassem pontos de vista não só diferentes mas eqüipolentes, o que não se encontra na concepção polifônica do sentido, da forma apresentada por Ducrot.

Não podemos descuidar de que a questão polifônica em Ducrot se insere no quadro maior de sua preocupação teórica com a questão da argumentatividade como um ato lingüístico fundamental, inscrito na própria língua e estruturador do discurso. Assumidos esses pressupostos, Ducrot teve a preocupação de avisar que faria "uma extensão, (bastante livre) à lingüistica, dos trabalhos de Bakhtin e sobre a literatura" (Ducrot-1987, p. 163). Afinal, enquanto Ducrot desenvolve uma concepção enunciativa do sentido, no quadro do dialogismo bakhtiniano o sentido é trabalhado como um produto da interação entre os sujeitos falantes. "Não bastasse isso, o estatuto teórico atribuido ao sujeito ć diferente nos dois autores. Na tipologia do sujeito de Ducrot não há qualquer consideração ideológica, pois nela o "indivíduo empírico" é um sujeito lingüístico e não um ser da linguagem.

O objeto sobre o qual se debruça Ducrot é o enunciado isolado; para Bakhtin o enunciado é um elo na cadeia interminável da comunicação verbal. Isolar esse enunciado é, na feliz imagem de Bakhtin, como arrancar do solo uma planta. Ducrot e Bakhtin, a partir de uma produção teórica complexa, produtiva e particular a cada um, realizam coisas diferentes, segundo critérios diferentes, chegando obviamente a resultados diferentes.

10 Reforçamos nossa posição, sugerindo que haveria maior precisão se, ao invés de polifonia, fosse utilizado homofonia, onde as várias vozes da enunciação estariam submetidas à do autor empirico.

11 Para um aprofundamento dessa discussão ver Gardin(1988) Le Sens comme production sociale. 


\section{A POLIFONIA NO BRASIL}

Como as tendēncias lingüisticas no Brasil que discutem o discurso são pouco preconceituosas quanto à inspiração teórica que as anima, o conceito de polifonia por elas utilizado invariavelmente deve tributos a uma dessas três matrizes analisadas, quando não a todas elas. ${ }^{12}$

Nas leituras, tanto se vê polifonia como um outro termo para dialogismo, como também polifonia distinguida de dialogismo e confundida com camavalização. ${ }^{13}$ Não é raro a aplicação de polifonia em seu mero sentido etimológico de "muitas vozes", como se encontra também polifonia como um "fenómeno" da intertextualidade que pode se manifestar de "maneira ampla ou restrita". (Koth-1986, p. 44). ${ }^{1}$

Quanto à monofonia, (que contraposta à polifonia, compōe o instrumental teórico de correntes lingüisticas surgidas sob o impulso da Análise do Discurso e que discute uma "teoria da enunciação"), embora não se trate de um termo comum na música, ${ }^{15}$ é possivel correspondê-la com a monodia. Sendo a monodia um canto em unissono, ficaria sacrificado o dialogismo constitutivo da linguagem. Devemos, neste caso, esquecer a música ou reelaborar a metafora, pois polifonic/monofonia participam de uma reflexão sobre o discurso que pressupōe a natureza dialógica da palavra, prevendo o seu "mascaramento" num processo denominado de monofonizaçāo da polifonia enunciativa. ${ }^{16}$

Como se vê, a pouca parcimônia no uso da metáfora the concedeu uma inconveniente maleabilidade que dificulta o estudo lingüístico, pois o leitor se sente lançado num verdadeiro pàntano conceptual.

É possivel perceber, mesmo assim, permeando essas variadas formulaçōes sobre a polifonia, um desejo, muito pouco explicitado, do

12 Pode-se perceber que o longo salto de uma polifonia, como mera sobreposição de vozes de um mesmo sujeito (Ducrox). para a polifonia, como manifestaçào da contradição constitutiva do sujeito (AD), é tentado com a "politizaçào" do sujeito ducroniano via metáfora bakhtiniana.

13 Os Anais da ANPOL-USP de 1992 oferecem significativos exemplares de quão voluvel tomou-se o conceito.

14 Roulet tambem fala em polifonia no sentido restrito distinguindo-a de diafonia (Roulet-1992, p. 68). Como diz Authier-Revuz, a metáfora musical esta em toda parte: diafonia é o nome atribuido às primeiras manifestaçōes polifónicas de que se tem noticia, também conhecidas como organum primirivo.

15 Quando Pahlen fala em "melcdia monofónica"(1965. p. 92), refere-se a uma espécie de monodia com acompanhamento praticada no secculo XVIII.

16 Ver Brandäo-1991, p. 67 e Guimaräes-1985. 
estabelecimento de um elo, ainda que tênue, com a gênese da metáfora, localizada em Bakhtin e Lacan, uma vez que a dificuldade do consórcio com Ducrot é mais evidente. Porém, a feliz utilização da metáfora pelos dois primeiros, não garante, por si só, a solidariedade de seus pensamentos. $O$ conceito de polifonia em Bakhtin vincula-se a uma concepção de sujeito própria de Bakhtin e que, com certeza, se afasta da noção de um sujeito dividido, efeito da linguagem, com uma fala fundamentalmente heterogênea.

O dialogismo bakhtiniano, se constata a alteridade constitutiva do discurso (descartando, também, uma concepção subjetivista de enunciado), não implica o pressuposto psicanalítico da divisão do sujeito, tampouco a submissão incondicional deste à linguagem, ${ }^{17}$ o que significaria aceitar o sistema da língua se sobrepondo ao sujeito.

A psicanálise busca, na polifonia não intencional da aparente linearidade de uma cadeia significante, a manifestação do inconsciente. Bakhtin vê, na palavra, o resultado polêmico de um embate social, pois dada a dialética interna constitutiva do signo, o ser não apenas se reflete na linguagem, mas também nela se refrata. A polifonia, que Lacan percebe nas pautas de uma partitura discursiva, e que permite acesso a uma interioridade subjetiva cindida, Bakhtin vê no território carnavalizado da linguagem, onde individualidades imiscíveis se confrontam e se mesclam num jogo de interação sócio-ideológica. Enquanto para Lacan "a linguagem com sua estrutura preexiste à entrada que nela faz cada sujeito a um dado momento de seu desenvolvimento mental" $(1978$, p. 225); para Bakhtin a linguagem está sendo construída e recriada a cada momento pelos falantes, pois é o produto social, coletivo e histórico de um processo vivo, em constante mutação, que se desenvolve na interação comunicativa. A linguagem, para Bakhtin, não existe por si mesma, como um objeto pronto $\mathrm{e}$ acabado. Quando Lacan postula que o mundo das palavras cria o mundo das coisas, coloca um vestal idealista neokantiano. Isto vai situá-lo irremediavelmente $\mathrm{cm}$ oposição à Bakhtin, para quem a linguagem, mais que organizadora, é produto da atividade humana.

Não cabe neste artigo o aprofundamento dessa discussão sobre a compatibilidade entre diferentes correntes de pensamento. Queremos, sim, chamar a atenção para a impropriedade de se tentar a aproximação de teorias lingüísticas, dificilmente entrelaçávcis, com a articulação de uma metáfora,

17 Na expressão de Lacan, o sujeito è "servo" da linguagem (1978, p. 226). 
como se fora um salvo-conduto que permitisse o trânsito pelas mais diversas áreas da ciència da linguagem.

\section{EPÍLOGO}

Dentre os vários e ricos ensinamentos de Bakhtin, um dos que mais tem sido seguido é o que se refere à questāo da autoria. Bakhtin afirma que a construção do nosso discurso se dả a partir da apropriação da palavra alheia. Com essa absolvição prévia concedida por Bakhtin, permitiu-se uına utilizaçāo exageradamente livre dos seus ensinamentos, resultando, muitas vezes, em um distanciamento das premissas originais. Acresce-se a isso a própria natureza multifacetada da produçāo intelectual de Bakhtin, que pouco contribuiu para a definição precisa de seus conceitos.

Em PPD, como vimos, Bakhtin opōe à polifonia, indistintamente, homofónico e monológico, dando preferència a este. Nas outras obras de Bakhtin, inclusive naquelas assinadas por seus parceiros do Circulo, monológico é contraposto a dialógico, sem qualquer menção à polifonia.

Se a metáfora musical parece ter ficado reservada por Bakhtin para caracterizar o romance de Dostoiévski, não signilica que o conceito deva confinar-se ao universo da teoria literária. $O$ importante é que, fora desse domínio, não se perca de vista que o conceito de polifonia de Bakhtin compōe a mesma perspectiva dialógica de sua concepção de linguagem, ou seja, o dialogismo bakhtiniano é polifonico e camavalesco.

\section{RESUMO}

O objetivo deste trabalho é recuperar o sentido da polifonia trazido da música medieval e mostrar a sua aplicaçāo metafórica por Bakhtin, na analise da obra de Dostoievski, e por Lacan, na caracterizaçào do inconsciente.

Sendo hoje a polifonia um conceito corrente entre varias correntes lingüisticas, buscamos tambem neste artigo apontar possiveis improcedencias na tentativa de aproximação de linhas teriricas, através da ariculaçào desisa metáliora. 


\begin{abstract}
The aim of this work is to clarify the meaning of poliphony brought about by medieval music and to show its metaphorical application by Bakhtin, in his analysis of Dostoiévski's work, and by Lacan in its characterization of the unconscious.

Considering that poliphony is nowadays a current concept in various linguistic trends, this article points at some groundless procedure detected in the attempt to bring different theoretical lines together by means of the ariculation of this metaphor.
\end{abstract}

\title{
REFERÊNCIAS BIBLIOGRÁFICAS
}

AUTHIER-REVUZ, Jacqueline. "Heterogeneite montree et herogeneite constitutive: elements pour une approche de lautre dans le discours". In: DRLAV - Revue de linguistique Centre de recherche de l'université de Paris VIII, 1982. n.26. p.91 a 151.

.Heterogeneidade(s) anunciativa(s)".In Cademos de Estudos Lingü̈́sticos n. 19, p.25 a 42, Unicamp, 1990.

BACHELARD, Gaston. La formación del espiritu cientifico - contribuicion a un psicoanálises del conocimiento objetivo. Buenos Aires: Argos, 1948.

BAKHTIN, Mikhail.Problemas da poética de Dostoiévski, Rio de Janeiro: Ed.ForenseUniversitäria, 1981.

. A cultura popular na Idade Média e no Renascimento. O comtexto de François Rabelais

- Brasilia: Hucitec, 1987.

BRANDẢO. Helena H. Nagamine. Introluçâo a análise do discurso. Campinas: Edit. da Unicamp, 1991.

DUCROT, Osvald. "Esboço de uma teoria polifờnica da enunciação". In: $O$ dizer $e$ o dito. Campinas: Ponte Editores, 1987. - cap.VIII. p.161-210,

GARDIN, B. Le sens comme production sociale. In: $L I N X$, n. 19, p. 55 a 72, Universitè de Paris, Ling. Institute Nanteme X, 1988.

GROSSMAN, Leonid. Dostoiev'ski arrista. Rio de Janeiro: Civilização Brasileira, 1967.

GUIMARÃES, Eduardo. "Polifonia c tipologia textual". In: Cadernos PUC. São Pauln. n. 22. p. $75-87,1985$.

KIEFER. Bruno. História e significado das formas musicais; do moteto gótico à fuga do século $X X$. Movimento, Porto Alegre: Instituto Estadual do Livro, 1976.

KOCH, Ingedore Grunfeld Villaça . A intenextualidade como fator da textualidade. In: Cadernos PUC, São Paulo, n. 22, p. 39-46, 1985.

KOTHE, Flivio René. Literatura e sistemas imtersemióticos. São Paulo, Conez, 1981.

LACAN, Jacques. A instäncia da letra no inconsciente ou a razào desde Freud. In: Escritos. S.Paulo: Penpectiva, 1978.p.223-59. (Col. Debates).

MAINGUENEAU, D. Polyphonic. In: Elements de linguistique pour le texte lineraire, Paris: Bordas, 1990.p.69 a 83.

PAHLEN, Kun. História universal da muisica. Sāo Paulo: Melhoramentos, 1965. 
ROULET. Eddy. Vers une approche modulaire de l'analyse du discours. In: Cahiers de Linguistique Fraņ̧aise, Gènève. Universite de Gènève: n. 12, p.53-83, 1991.

STAROBINSKI. Jean. As palavras sob as palavras - as anagramas de Fendinand de Saussure.

São Paulo: Perspectiva, 1974. (Col. Debates-critica).

WISNIK, José Miguel. O som e o semiido. São Paulo: Cia das Letras. 1989. 